\title{
The Pollino 2012 seismic sequence: clues from continuous radon monitoring
}

\author{
Antonio Piersanti, Valentina Cannelli, and Gianfranco Galli \\ Istituto Nazionale di Geofisica e Vulcanologia, Rome, Italy \\ Correspondence to: Antonio Piersanti (antonio.piersanti@ingv.it)
}

Received: 4 May 2016 - Published in Solid Earth Discuss.: 12 May 2016

Revised: 12 July 2016 - Accepted: 12 July 2016 - Published: 6 September 2016

\begin{abstract}
The 2012 Pollino (Calabria, Italy) seismic sequence, culminating in the Mw 5.2 earthquake of 25 October 2012, is investigated, exploiting data collected during a long-term continuous radon monitoring experiment performed in the epicentral area from late 2011 to the end of 2014. We analyse data collected both using a phenomenological approach based on quantitative evidence and a purely numerical analysis including the following: (i) correlation and cross-correlation investigations; (ii) an original approach aimed at limiting the impact of meteorological parameters variations on the interpretation of measured radon levels; (iii) a change point analysis; (iv) the implementation of an original detection algorithm aimed at highlighting the connections between radon emission variations and major seismic events occurrence. Results from both approaches suggest that radon monitoring stations can be subject to massive site effects, especially regarding rainfall, making data interpretation harder. The availability of long-term continuous measurements is crucial to precisely assess those effects. Nevertheless, statistical analysis shows a viable approach for quantitatively relating radon emanation variations to seismic energy release. Although much work is still needed to make radon time series analysis a robust complement to traditional seismological tools, this work has identified a characteristic variation in radon exhalation during the preparation process of large earthquakes.
\end{abstract}

\section{Introduction}

One of the most challenging problems in seismology is presently the study of preparatory processes for strong earthquakes. Seismometric data still represent the most informa- tive observations available to researchers who investigate their association with signals emitted by faults before catastrophic ruptures. In this respect, new features in seismometric records have been discovered and studied in the recent past (Guilhem et al., 2008; Lucente et al., 2010; Fuchs et al., 2014). Beside seismometric recordings, slow deformation observations and laboratory experimental simulations contributed to give new important pre-seismic information (Chlieh et al., 2004; Liu et al., 2004; Tserolas et al., 2012; Jebur et al., 2014; Spagnuolo et al., 2015). Nevertheless, the physical processes taking place on time scales ranging from few years to few hours before the seismic rupture still remain mostly unknown.

Evidence gathered in recent years indicates that, in specific seismotectonic settings, fluid transport and dynamics could play an important role in seismogenic processes (Miller et al., 2004; Stefansson, 2011; Lewicki et al., 2014; Shelly et al., 2015). In these seismogenic systems, the study of transient signals associated with fluid migration (markers) becomes particularly significant. Among all the possible transient signals, the radioactive nature of radon makes it a potentially extremely efficient marker to study and monitor fluid flows. Indeed, radioactive detectors are generally quite efficient and accurate instruments, and their implementation and installation requirements make them also particularly competitive in terms of operating costs. A radon monitoring station equipped with meteorological sensors presently costs almost one order of magnitude less than a $\mathrm{CO}_{2} / \mathrm{O}_{3}$ geochemical station (Bourcier et al., 2011; Celia et al., 2015). The cost factor becomes particularly important considering that the experience in operating seismometric and geodetic observational networks taught us that, in order to achieve high quality results, instrumentally dense networks are needed. 


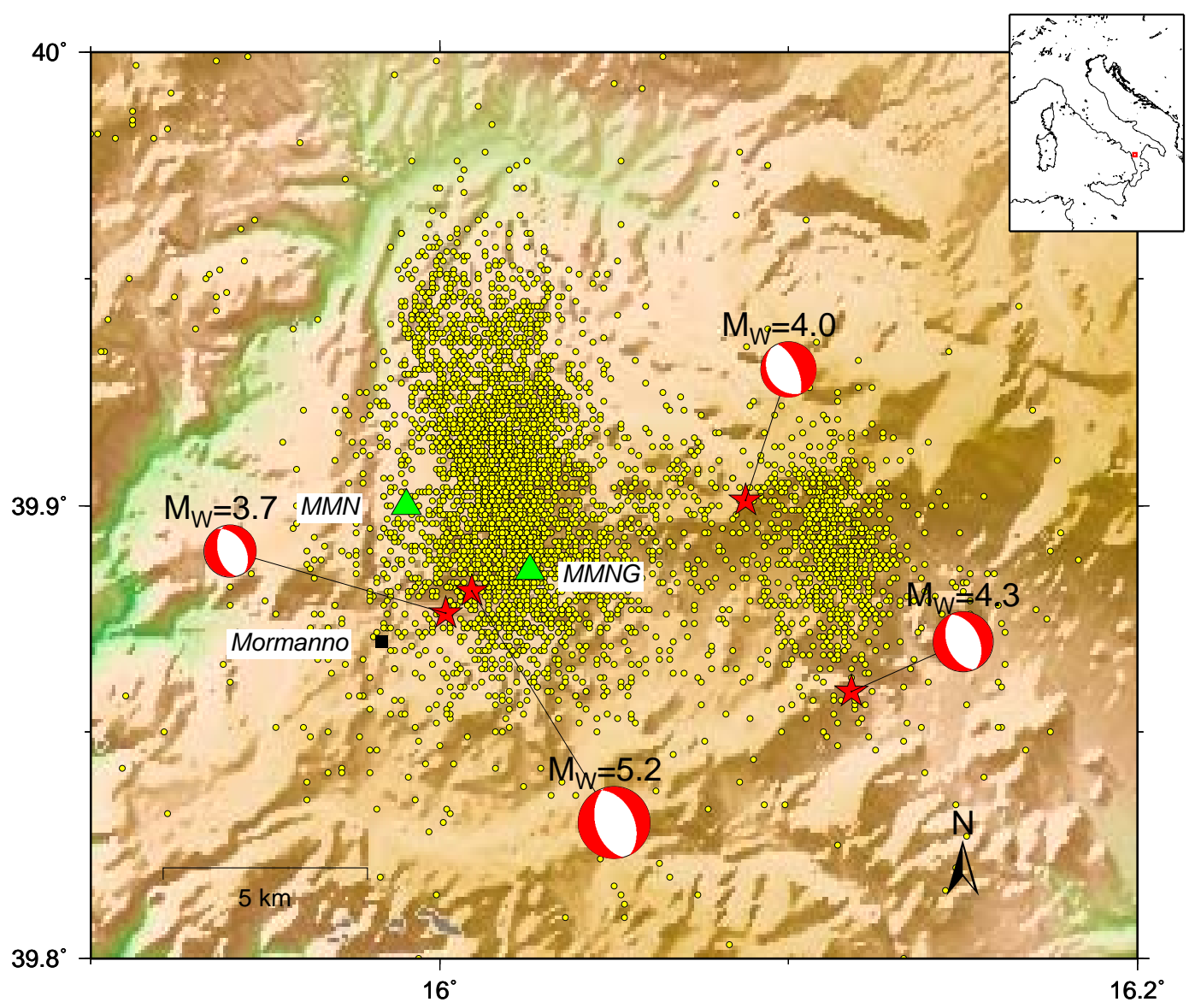

Figure 1. Geographical setting of the study area located in the Calabria peninsula, southern Italy (see inset). Green triangles show the location of a radon monitoring stations MMN and MMNG. Yellow circles represent the earthquakes recorded by ISIDe (2010) between December 2011 and October 2014 with epicentral distance from MMN (the older station) less than or equal to $15 \mathrm{~km}$ (4800 events). Focal mechanisms of the Mw 4.3 28 May 2012, Mw 5.2 25 October 2012, Mw 3.7 4 June 2014 and Mw 4.06 June 2014 earthquakes (http: //cnt.rm.ingv.it/tdmt.html) are also represented.

From the beginning of 2010 the Pollino Range area, in the southern Apennines on the border between Calabria and Basilicata, has experienced a seismic sequence. The seismic activity is characterized by frequent periods of intense output with others of relative quiescence and culminated on 25 October 2012 with a Mw 5.2 mainshock (Tertulliani and Cucci, 2011; Totaro et al., 2015). From 2010 to the end of 2014 about 5000 events (mostly ML $\leq 3.0$ ) were recorded (ISIDe, 2010). The hypocenters clearly show two main clouds (see Fig. 1): a western cluster which includes most of the seismicity (the Mw 5.2 mainshock too) and seems consistent with a normal faulting trending NNW and dipping WSW and an eastern cluster, including the Mw 4.3 earthquake occurred on 28 May 2012 that does not clearly exhibit instead a definite fault plane (Totaro et al., 2013, 2015). During 2014, two other significant events took place in the area: Mw 3.7 and Mw 4.0 earthquakes on 4 and 6 June on the western and eastern cluster, respectively. Recently Totaro et al. (2015) relocalized the hypocenters of the 2010-2013 swarm revealing two main clusters, differing both in number and in magnitude distribution of seismic events. The two different clusters of values for magnitude and total number seem to suggest that two distinct structures of different dimensions have been activated, as supported by the Gutenberg-Richter law too.

In late 2011, we started a long-term experiment in the Pollino area of Southern Italy, installing a high sensitivity, high efficiency active radon monitoring station based on a Lucas cell (Lucas, 1957; Semkow et al., 1994; Abbady et al., 2004). In November 2012, a second station was installed a few kilometres away from the first one.

Several world-wide compilations of radon emission anomalies that could be associated with variations in the seismic activity and/or occurrence of a single earthquake are available in the literature (see Cicerone et al., 2009, for a review). In recent years, laboratory experiments gave unambiguous evidence of the relation between the rock state of stress and variations in the radon emanation properties (Tuccimei et al., 2010; Mollo et al., 2011). 
It is widely accepted that meteorological parameters play an important role in modulating soil radon emanations (Singh et al., 1988; Zmazek et al., 2003; Cannata et al., 2009; Jaishi et al., 2014; Piersanti et al., 2015). But, as evidence grows, it becomes clearer that this relation is complex and strongly site dependent, so it cannot be steadily assessed. Even the relative importance among the main relevant variables (temperature, precipitation, pressure) in modulating the radon emissions cannot be univocally determined and it is likely to be site dependent, since different analyses led to different results (i.e., Zafrir et al., 2013; Jaishi et al., 2014; Kumar et al., 2015; Piersanti et al., 2015).

In the following, we propose an articulate approach, taking advantage of different investigative tools, to better assess the questions described above. In particular, we will consider the problem both from a quantitative phenomenological point of view and by means of suitable numerical analyses. The presentation of our results is organized as follows: in Sect. 2 we describe the observational setup, the collected radon time series and some phenomenological insights about the impact of meteorological conditions on the detected signal. In Sect. 3 we analyse time series by means of different numerical approaches: namely, in Sect. 3.1 we perform a correlation and cross-correlation analysis between radon emanation observations and the other relevant observables (meteorological parameters and seismic moment release) and successively we outline an approach aimed at reducing meteorological effects in the measured radon time series; in Sect. 3.2 we investigate the potential predictive capability of the radon signals, testing the possibility of highlighting in advance the occurrence of the major events of the seismic sequence in the Pollino area from the radon time series analysis. Finally, in Sect. 4 we discuss and summarize all our findings.

\section{MMN and MMNG sites}

We installed two radon monitoring stations in the Pollino area, equipped with prototype detectors based on a Lucas cell that continuously acquired radon concentration data, with a sampling interval of 2 hours. Station MMN was colocated with the homonymous seismic station belonging to the INSN, Italian National Seismic Network, at Mormanno $\left(39^{\circ} 53^{\prime} 58.6^{\prime \prime} \mathrm{N} 15^{\circ} 59^{\prime} 25.5^{\prime \prime} \mathrm{E}\right)$ in December 2011, at about $921 \mathrm{~m}$ above sea level. Station MMNG was installed in October 2012 (just after the Mw 5.2 event) about $3.0 \mathrm{~km}$ east of MMN (39 53'8.1' $\left.\mathrm{N} 16^{\circ} 1^{\prime} 33.6^{\prime \prime} \mathrm{E}\right)$, at about $858 \mathrm{~m}$ above sea level. Both stations are shown in Fig. 1 with green triangles. The complete time series and technical features characterizing the MMN and MMNG stations are reported in the Supplement.

Station MMN shows a high variability in radon concentration, with sharp peaks and rapidly changing values ranging from a few tens up to $2500 \mathrm{~Bq} \mathrm{~m}^{-3}$ (see Supplement Fig. S1), while MMNG station has lower concentration values (up to
$600 \mathrm{~Bq} \mathrm{~m}^{-3}$ ) and a trend ascribable to a major seasonal correlation with temperature (see Fig. S2), as laboratory tests (Iskandar et al., 2004) and long-term radon monitoring studies (Cannata et al., 2009; Jaishi et al., 2014; Pitari et al., 2014; Piersanti et al., 2015) would indicate.

The evidence of the impact of meteorological parameters on radon observations and at the same time the strong sitedependent nature of the characteristics of radon emissions introduce uncertainties into the comprehension of the problem. These complexities suggest the problem should be approached from a phenomenological point of view in order to supplement the indications retrieved by means of a purely quantitative analysis. First of all, we focus on the "sealing" effect induced by precipitation on soil radon emanation. Such effect has already been suggested and established by several studies (i.e., Inan et al., 2012; Kumar et al., 2015), and its impact in the MMN time series seems particularly evident. Figure 2 shows a collection of selected periods from MMN time series (radon in concentration $\left[\mathrm{Bq} \mathrm{m}^{-3}\right] / 115 \mathrm{~min}$ ) corresponding to major rainfall episodes. From Fig. 2 it is clear that, after a major precipitation episode (red ellipses), radon concentrations drastically fall by a factor greater than 10 up to a factor of almost 100. Precipitation, as well as all of the meteorological parameters discussed here, is obtained as short term (12-24 h) weather forecast by an Italian weather forecasting site (http://www.ilmeteo.it/). Figures 2a, $\mathrm{b}, \mathrm{c}$ and $\mathrm{d}$ represent fall-winter heavy rain events, which are common in this region (Federico et al., 2008; Terranova and Iaquinta, 2011; Vennari et al., 2014), whilst Figs. 2e and f show spring-summer time windows, when shorter and less intense rain episodes occur. Despite the different magnitude of precipitation episodes, similar reduction effects in radon emission can be seen in fall-winter as well as in springsummer periods. Moreover, it can be seen that during prolonged dry periods, independently from the season, radon concentration peaks are more pronounced (yellow rectangles). For the MMNG station the reduction effect of rainfall on radon observations seems less marked, but it is still present. Figures $3 \mathrm{a}, \mathrm{b}, \mathrm{c}$ and $\mathrm{d}$ show selected fall-winter and spring-summer periods for MMNG, respectively. In this case, though the reduction of radon emission with precipitation is still present (Fig. 3a), heavy rain events cannot be clearly separated from radon concentration peaks, being sometimes overlaid (yellow rectangles) (Figs. 3b, c and d). Anyway, overall both stations have evidenced that radon activity was on average higher during the summer than the winter, in according with observations by Zafrir et al. (2013) and more recently by $\mathrm{Oh}$ and Kim (2015) and Piersanti et al. (2015). The complete explanation of this behaviour involves complex interactions among all environmental parameters. Nevertheless, it is likely that a partial role is played by the inhibitory effect of the rain on radon emanation. Of course, this effect is much smaller in dry season than in winter. 

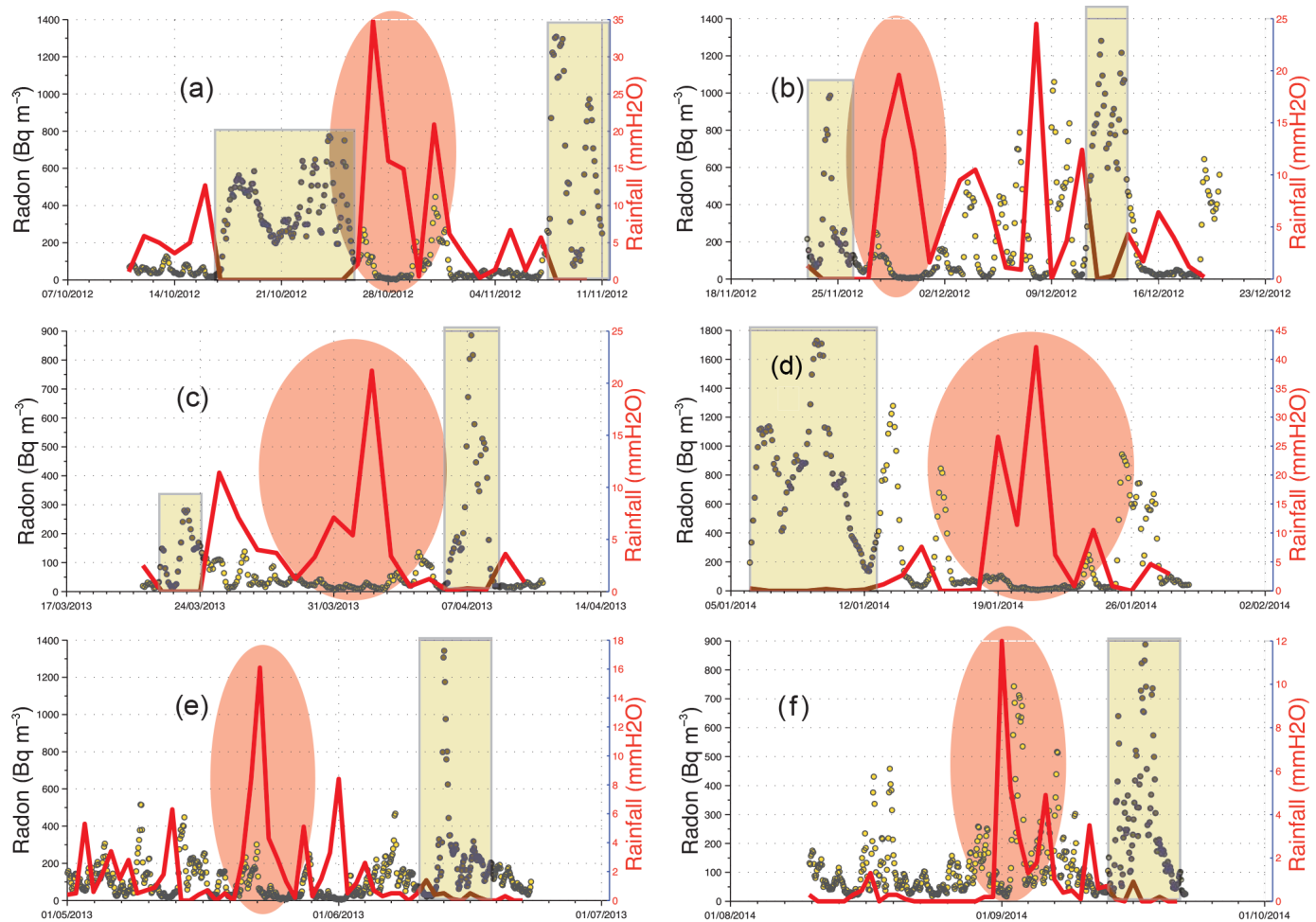

Figure 2. MMN radon concentration in $\left(\mathrm{Bq} \mathrm{m}^{-3}\right) / 115 \mathrm{~min}$ (yellow dots) and daily average rainfall (red line) for some significant fall-winter (a-d) and spring-summer (e, f) periods (see text for details). Red ellipses mark heavy rain events, whilst yellow rectangles represent radon concentration peaks.
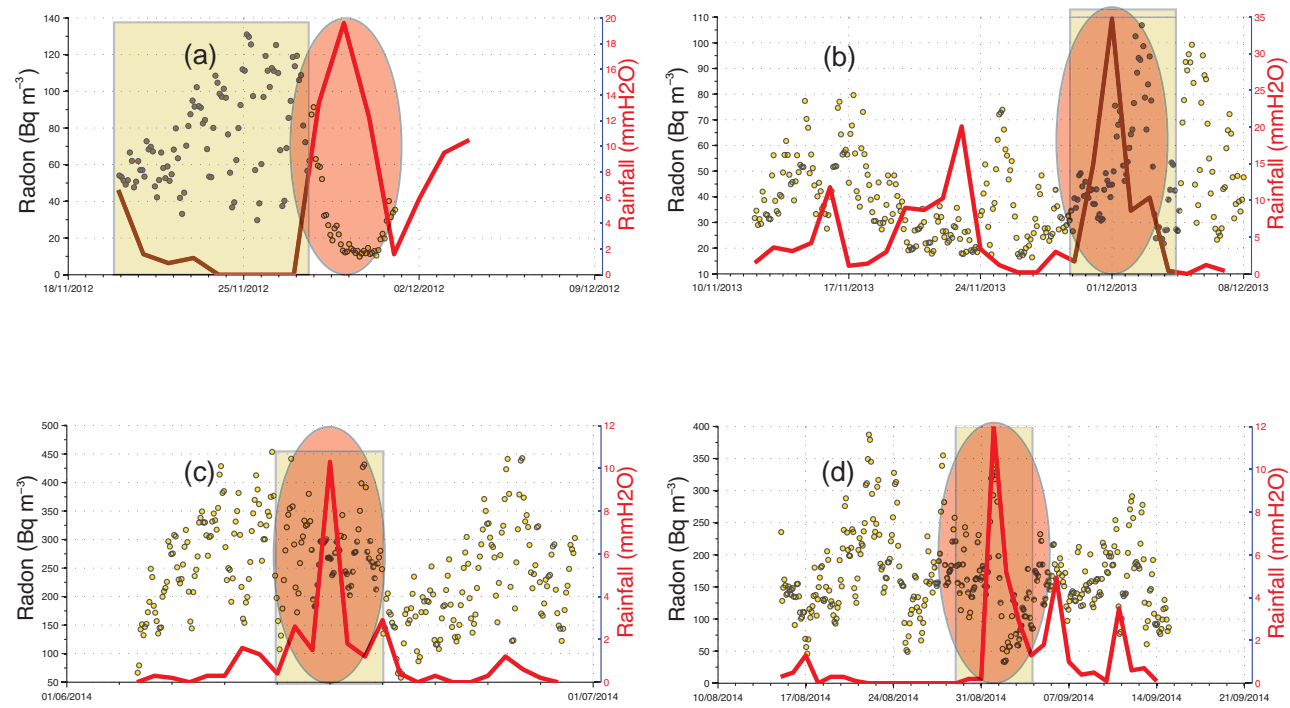

Figure 3. MMNG radon concentration in $\left(\mathrm{Bq} \mathrm{m}^{-3}\right) / 115 \mathrm{~min}$ (yellow dots) and daily average rainfall (red line) for some significant fallwinter (a, b) and spring-summer (c, d) periods (see text for details). Red ellipses mark heavy rain events, whilst yellow rectangles represent radon concentration peaks.

\section{Analysis of radon time series}

In the following we try both to assess the impact of meteorological parameters on radon signals on a quantitative basis and to outline an original approach aimed at removing (or at least mitigate) the effects of meteorological events on the detected time series. Our goal is to maximize the informative 

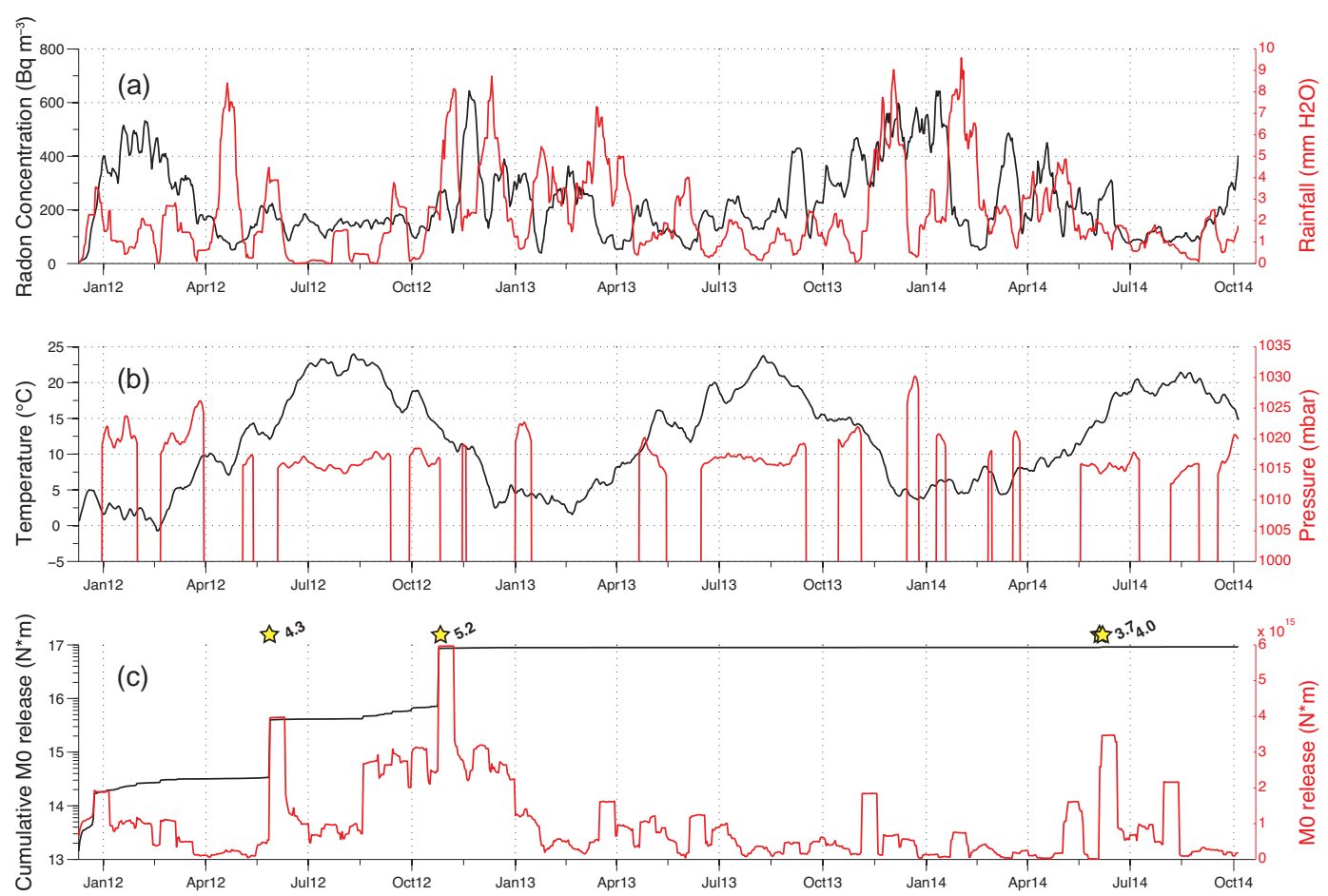

Figure 4. (a) 14-day moving-averaged time series of radon concentration at MMN (black line) and of rainfall (red line). (b) 14-day movingaveraged time series of temperature (black line) and pressure (red line). (c) 14-day moving average of cumulative seismic moment release (black line, in logarithmic scale) and of seismic moment release (red line). Yellow stars represent the occurrences of the main earthquakes of the sequence.

power of radon emanation variations potentially related to a variation in seismic energy release.

Even though the effects of meteorological conditions on temporal radon time series have been investigated for the last 50 years by means of different approaches and methodologies (Singh et al., 1988; Zmazek et al., 2003; Piersanti et al., 2015), a clear assessment and a solid interpretation has not been univocally established yet.

For the following analyses, we decided to use only radon time series from station MMN, since it was the only one installed before the main events of the sequence (Mw 4.3 on May 2012 and Mw 5.2 on October 2012), corresponding to the major changes in cumulative seismic moment release rate (Fig. 4c). From data collected in the time window from April 2012 to December 2012 (Fig. 5a) that includes the two major seismic events, we note that in correspondence of these two change-points the radon emanation increased a few days before the seismic events. Both the average amplitude and duration of such increases appear to scale with the magnitude of the corresponding earthquakes, as highlighted in the two yellow rectangles of Fig. 5a. The apparent discontinuity in the radon increase just after the Mw 5.2 seismic event is likely to be associated with a major precipitation episode right after the earthquake occurrence. In fact, the severe rain event occurred just after the Mw 5.2 earthquake has likely interrupted the underlying radon increase characterized by a quasi-linear trend starting from the beginning of October (therefore almost a month before the mainshock) until the end of November 2012 with just the only exception of the week after the $35 \mathrm{~mm} \mathrm{H}_{2} \mathrm{O}$ peak rain episode (Fig. 5c). Figures $5 \mathrm{~b}$ and $\mathrm{c}$ show in detail the time windows corresponding to the two seismic events. The intensity of radon emanation sharply increases about $24-48 \mathrm{~h}$ before the occurrence of both earthquakes, reaching similar peak values (800-900 $\mathrm{Bq} \mathrm{m}^{-3}$ ) and then, in the case of the 28 May $2012 \mathrm{Mw} 4.3$, it returns to previous values after about 7 days, while, after the mainshock of the 25 October 2012 Mw 5.2 event, observed values continue to increase up to about $1600 \mathrm{~Bq} \mathrm{~m}^{-3}$ for more than 30 days after the earthquake (except, as described above, for the first few days of November, when a major precipitation event flattened down radon levels). While not quantitatively constrained yet, it is reasonable to assume that the time needed for radon emanation to recover from the perturbed state returning to background level is proportional to the overall energy involved in the seismogenic processes and hence to the magnitude of the impending earthquake.

\subsection{Correlation and cross-correlation analysis}

In order to quantitatively assess the phenomenological evidences described above by means of numerically objective 

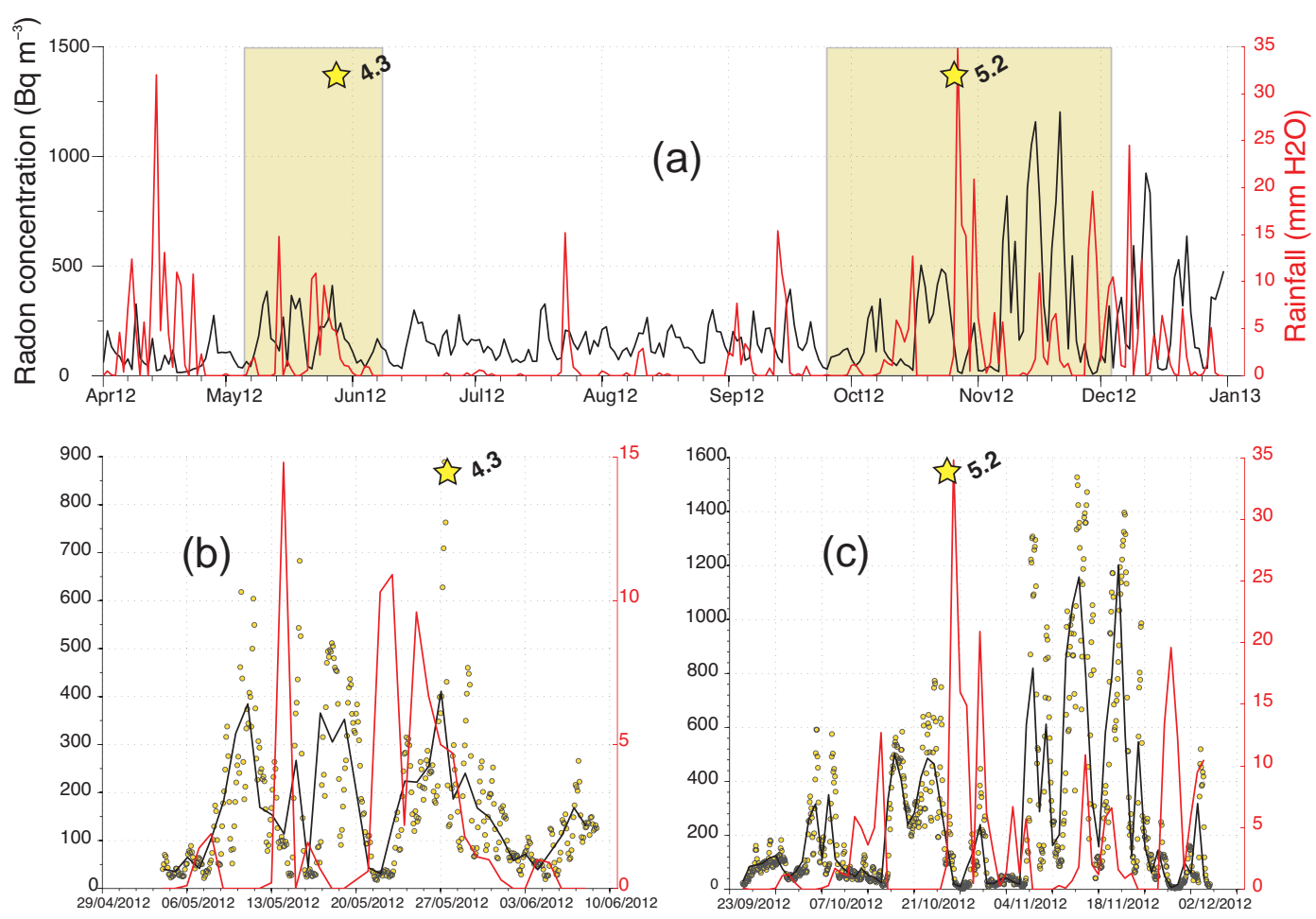

Figure 5. (a) Time series of daily moving-averaged radon concentration at MMN (black line) and of rainfall (red line) for the period between 1 April 2012 and 31 December 2012. Yellow stars represent the occurrences of the two main earthquakes of the sequence. (b) an enlarged

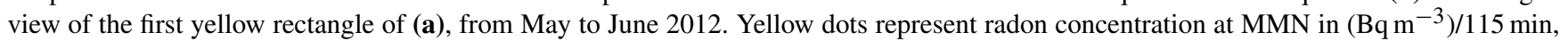
while a black line shows the daily averaged concentration. Daily averaged rainfall levels are represented by a red line. (c) An enlarged view of the second yellow rectangle of (a), from September to December 2012, as in panel (b).

procedures, we perform a series of statistical evaluations on our dataset. Figure 4 shows the whole time series employed in the statistical analysis filtered with a 14-day moving average. All the moving averages employed in our computations are evaluated backwards (i.e., average at day $d_{i}$, employs only the previous $\left(d_{i}-14\right)$ days). Figure 4 a represents the radon concentration (black line) and rainfall (red line), Fig. $4 \mathrm{~b}$ shows temperature (black line) and pressure (red line). Figure $4 \mathrm{c}$ shows the cumulative seismic moment release (black line) with the seismic moment release (red line).

Since the Pearson coefficient reflects mainly a linear relationship between variables, we estimated the correlation between variables using both the Pearson coefficient (Hollander et al., 2014) and a non-parametric correlation coefficient (Kendall, 1970). The two approaches yield virtually identical results, so we show here only the classical Pearson analysis. We performed both a correlation analysis between radon and environmental parameters and a cross-correlation analysis between radon, meteorological parameters and seismicity. All analyses look for a linear relationship between two variables, but the cross-correlation considers it to be a function of the time offset of one relative to the other. Formally cross- correlation function reads (i.e., Chatfield, 2004):

$$
C C_{u y}(k)=\left\{\begin{array}{ll}
\frac{1}{N} \sum_{t=1}^{N-k}\left(u_{t}-\bar{u}\right)\left(y_{t+k}-\bar{y}\right) & k=0,1, \ldots,(N-1) \\
\frac{1}{N} \sum_{t=1-k}^{N}\left(u_{t}-\bar{u}\right)\left(y_{t+k}-\bar{y}\right) & k=-1,-2, \ldots,-(N-1)
\end{array},\right.
$$

where $N$ is the series length, $u_{t}$ and $y_{t}$ are the two time series, $\bar{u}$ and $\bar{y}$ are their sample means, and $k$ is the lag. Differently from Pearson linear correlation, the cross-correlation coefficient is not normalized a priori: in order to grant compatibility with the previous analyses, we normalized the crosscorrelation coefficient here so that it varies between -1 and 1 and set the lag range between -40 and 40 days.

We decided to exclude rainfall from this analysis since, differently from other meteorological variables, it is intrinsically characterized by a strongly discontinuous, spike-like behaviour being the majority of the sampling times characterized by a null value. In fact, during the time window of our most relevant analyses, we have null rain values ranging from 65 to $75 \%$ of the sampling intervals (to compare for instance with less than $10 \%$ of days with null seismic moment release). This makes correlation and cross-correlation analysis inadequate approaches to evaluate the relationship between radon concentration and rainfall.

The results regarding the correlation analysis in terms of Pearson coefficient are summarized in Table 1. For all considered cases, we report both global cumulative value $(G)$ 

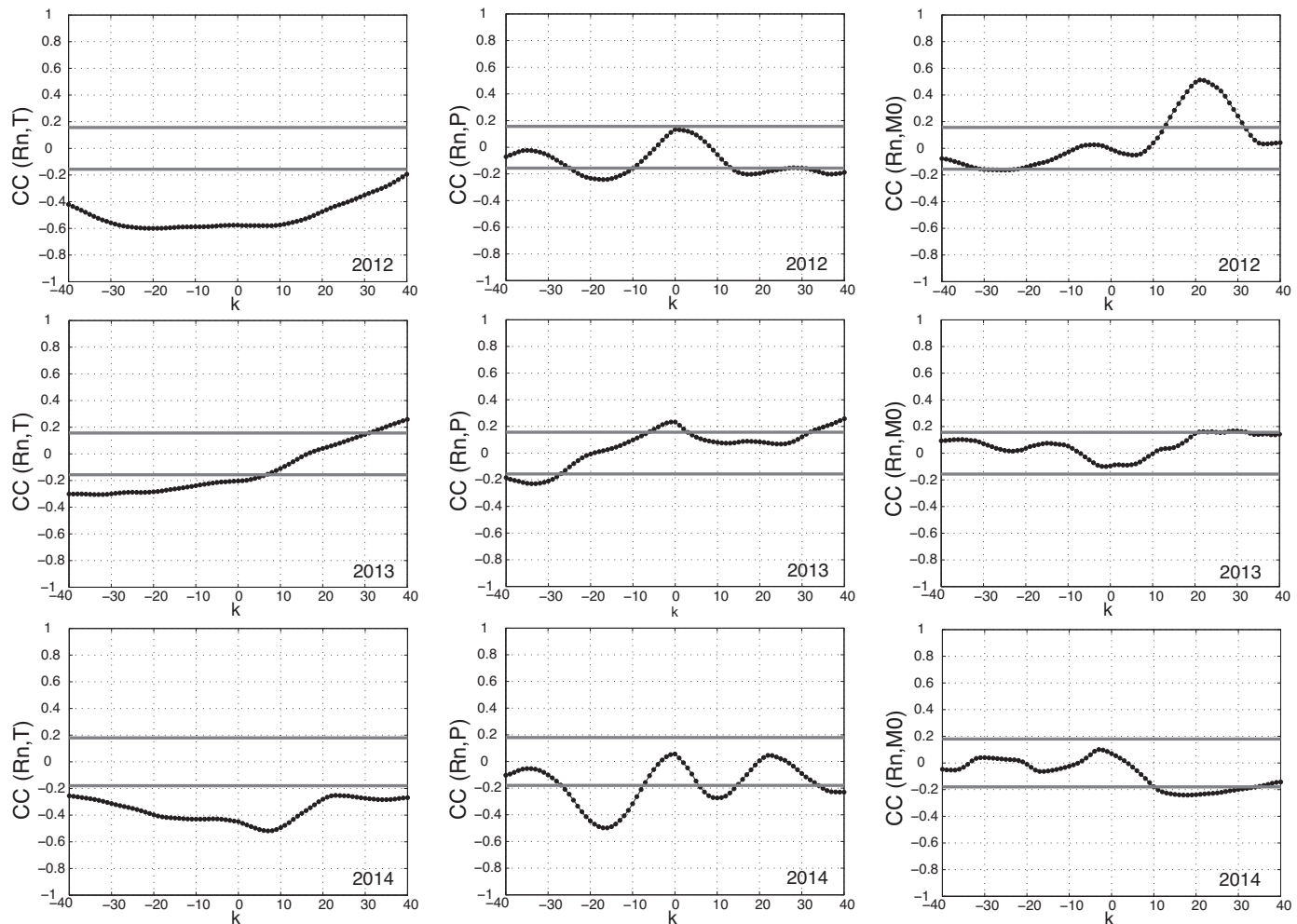

Figure 6. Cross-correlation function (CC) evaluated for 2012-2013-2014 separately, between radon concentration Rn and temperature $T$, pressure $P$ and seismic moment release $M_{0}$. The CC is evaluated between 14-day moving average filtered time series. Horizontal gray lines represent $99 \%$ confidence threshold.

Table 1. Pearson correlation coefficient $(\rho)$ between radon concentration time series $(\mathrm{Rn})$ and temperature $(T)$, pressure $(P)$ time series, evaluated both as global value $(G)$ for the entire acquisition window and as annual value for 2012, 2013, 2014 separately. Rn concentration, $T$ and $P$ time series are filtered with a 14-day moving average.

\begin{tabular}{lrrrr}
\hline$\rho$ & $G$ & 2012 & 2013 & 2014 \\
\hline$(\mathrm{Rn}, T)$ & -0.46 & -0.58 & -0.20 & -0.46 \\
$(\mathrm{Rn}, P)$ & 0.15 & 0.13 & 0.24 & 0.04
\end{tabular}

corresponding to the entire acquisition window (2012-2014) and separate results for each year (2012-2013-2014). The Pearson coefficient $\rho$ shows a significant level of negative correlation only between radon concentration and temperature with values ranging from -0.6 to -0.2 . The value of the Pearson coefficient for pressure, even though coherent both in sign and in magnitude for each time window, is nevertheless statistically compatible with zero.

Within the cross-correlation analysis, whose results are shown in Fig. 6, we include also the seismic moment release $M_{0}$, since for this physical variable a lagged approach is able to consider also a causal relationship in addition to an instantaneous feedback among variables (Box and Jenkins, 1976;
Piersanti et al., 2015). Figure 6 is arranged in nine panels: from left to right the cross-correlation between radon and temperature, pressure and seismic moment release, respectively, are presented, while the rows represent 2012, 2013 and 2014 time windows. No sharp and isolated peak is observed in Fig. 6, indicating that no clear cross-correlation scenario can be deduced from this analysis. Nevertheless, we can confirm the correlation pattern described above: the crosscorrelation function between radon concentration and temperature does not show clear preferences for a lag time, but it is almost always characterized by negative values, while the cross-correlation between radon and pressure time series varies in time, with value always below the $99 \%$ confidence level. The confidence level is defined as the value of the Pearson coefficient $\rho$ for which the probability of obtaining a cross-correlation greater than or equal to $\rho$ for uncorrelated data is equal to 1 (Chatfield, 2004) and is represented in Fig. 6 by the grey lines. The cross-correlation function between radon concentration and seismic activity shows a significative positive peak during 2012 (when the major seismic events occurred), with a maximum value of 0.5 in correspondence of a 21 day delay forward of radon concentration (Fig. 6, panel upper right).

Of course the relationship between variations of radon emanation and seismotectonic processes would be better as- 


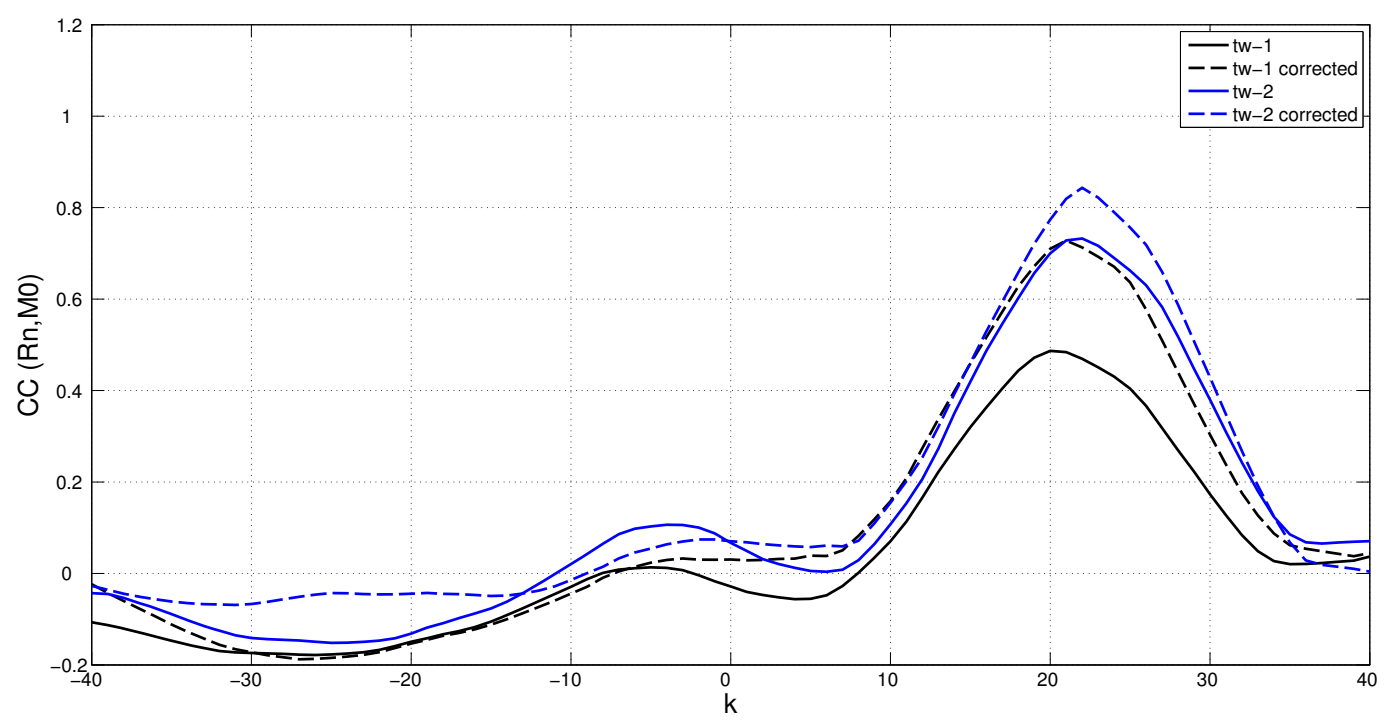

Figure 7. Cross-correlation function (CC) between radon concentration Rn and seismic moment release $M_{0}$ time series, filtered with a 14-days moving average and evaluated in two different time windows (black line for tw-1 and blue line for tw-2), with (dashed lines) and without (solid lines) correction coefficients. Both the values of correction coefficients and time windows bounds are summarized in Table 2 .

sessed if we would be able to remove, or at least reduce, the bias of meteorological parameters on the radon measured concentration. To this aim, we implement an empirical correction procedure for temperature, pressure and precipitation variations. Basically, given an observed radon concentration value $R n_{\text {obs }}$, taken at time $t$ when a temperature $T$, an atmospheric pressure $P$ and a precipitation level $R$ have been registered, we define a corresponding meteorological-corrected concentration $R n_{\text {cor }}$ as follows:

$\mathrm{Rn}_{\text {cor }}=\mathrm{Rn}_{\mathrm{obs}} \times C_{P} \times C_{R} \times C_{T}$,

where $C_{P}, C_{R}$ and $C_{T}$ are positive correction factors obtained as a simple linear interpolation from the minimum detected values of $T, P$ and $R$ in a selected time window where $\left\{C_{P}=C_{R}=C_{T}=1\right\}$ (that is to say there is no-correction), to the maximum detected values in the selected time window where $\left\{C_{P}=C_{P_{\max }} ; C_{R}=C_{R_{\max }} ; C_{T}=C_{T_{\max }}\right\}$. The optimal value of $C_{P_{\max }}, C_{R_{\max }}$ and $C_{T_{\max }}$ can be obtained by maximizing the cross-correlation function for the selected time window (of course a time window including a significant seismic activity must be selected). We want to note that the subscript "max" above stands for maximum magnitude of the correction, not for maximum absolute value of the correction parameter $C_{i}$. Indeed, if the correction factor corresponding to the maximum value of a given meteorological parameter $C_{i}$ is $>1$, it means a negative correlation between radon and that parameter, the opposite if the correction factor $C_{i}$ is $>1$. Since it is reasonable to consider the possible connection between radon concentration variations and seismotectonic processes as dependent from the seismic source-observer distance (Dobrovolsky et al., 1979), we have implemented in the correction procedure also the possibility of weighting for the epicentral distance (Hauksson and Goddard, 1981; Einarsson et al., 2008). Again, given an earthquake with seismic moment $M_{0_{\text {obs }}}$ occurred to an epicentral distance $r$ from station MMN, we consider a corresponding distance-weighted value $M_{0_{\mathrm{wgt}}}$ :

$M_{0_{\mathrm{wgt}}}=\frac{M_{0_{\mathrm{obs}}}}{r^{w}}$,

where $w$ is a positive weighting factor ( $w=0$ means no correction for epicentral distance).

In Fig. 7 we show the effects of our correction procedure on the cross-correlation function. The extrapolation of the optimal values for the correction parameters $C_{P_{\max }}$, $C_{R_{\max }}, C_{T_{\max }}$ and $w$ was performed by means of the MINUIT package (James, 1998), which implements a variable-metric method with an inexact line search, a stable metric updating scheme and a positive-definiteness check (Fletcher, 1970). The search domain for $C_{i}$ and $w$ was limited in the range between 0.1 to 10 to avoid unphysical solutions. This procedure has been applied with two different time windows, both including the two main events and the active part of the sequence (May 2012 Mw 4.3 and October 2012 Mw 5.2): the first time window (tw-1) covers a whole year from January 2012 to January 2013, while the second (tw-2) focuses on the most active part of the seismic sequence from April 2012 to January 2013. As can be seen from Fig. 7, the proposed correction procedure significantly increases crosscorrelation peaks for both time windows (indicated as tw-1 corrected and tw-2 corrected). Notably, the increase is greater for the larger time window where a lower (but still significant) peak cross-correlation value was obtained, while the time lag of the peak remains completely unchanged after 
Table 2. Correction coefficients for temperature $\left(C_{T_{\max }}\right)$, pressure $\left(C_{P_{\max }}\right)$, rainfall $\left(C_{R_{\max }}\right)$ and epicentral distance $(w)$ maximizing the cross-correlation function (CC) in time windows tw-1 (January 2012-January 2013) and tw-2 (April 2012-January 2013).

\begin{tabular}{rrrrr}
\hline & $C_{T_{\max }}$ & $C_{P_{\max }}$ & $C_{R_{\max }}$ & $w$ \\
\hline tw-1 & 2.4 & 4.4 & 10.0 & 1.3 \\
tw-2 & 5.6 & 0.9 & 9.0 & 0.0 \\
\hline
\end{tabular}

the correction, indicating that the variation of radon intensity seems to follow the variation in seismic moment release. In Table 2 the correction coefficient values maximizing the cross-correlation peak in the two time windows tw1 and tw-2 are reported. From the tabulated values we note the following: (i) the correction values for the rainfall lie in both cases at the top of the searching domain $\left(C_{R_{\max }}=10\right.$ for tw-1 and $C_{R_{\max }}=9$ for tw-2); i.e., rainfall is strongly anti-correlated with radon emanation, confirming the phenomenological analysis in previous Sect. 2; (ii) the correction values for the temperature are always greater than 1 , confirming that for MMN station temperature is anti-correlated with radon emanation (see above in this same section); (iii) the correction values for the pressure oscillate about $C_{P_{\max }}=1$, confirming the lack of a clear correlation regime between pressure and radon emanation for this station.

\subsection{Change point analysis and detection algorithm}

The problem of detecting changes in time series is well known in climate literature: the definition and identification of discontinuous steps, or change points, may be subjective and it also depends on the form of the trend one expects between changes. Several methods have been implemented to solve the change point problem both for short and long climatic time series. We refer the readers to Reeves et al. (2007), in which the literature about the change points methods is widely reviewed and discussed.

We applied to the measured radon intensity time series an algorithm developed in the realm of Earth's climate system studies in order to calculate, by means of a Bayesian approach, the posterior probability of multiple change points in a generic climatic time series (Bayesian Change Point algorithm, (Ruggieri, 2013), BCP hereinafter). Once the algorithm has identified an arbitrary number of change points in our time series, whose maximum is an input parameter of the algorithm $\left(k_{\max }=6\right.$ in the following), our primary interest is to verify if the detected change points in the radon time series are consistent with corresponding changes in cumulative seismic moment release rate (i.e., major earthquakes).

Applying the BCP algorithm to the whole MMN time series, we obtain an indication of most likely two change points that are potentially associable with the two largest events of the sequence. Figure 8 show the 14-day moving-averaged time series of radon intensity (solid black line) along with the change point regression model (dashed green line); the locations of the change points are displayed as red spikes, whilst earthquakes occurrences are displayed as yellow stars. Furthermore, the algorithm has the ability to provide an uncertainty estimate in locating a change point: in this case the height of the two considered spikes (the second and the third in Fig. 8) indicates a probability equal to 0.33 for the change point corresponding to the Mw 4.3 on May 2012 and a probability equal to 0.57 for the change point corresponding to the Mw 5.2 on October 2012. The second change point occurs on 8 May 2012, 20 days before the Mw 4.328 May, while the third change point occurs on 22 October 2012, 3 days before the Mw 5.2 25 October event.

The different time advances of the change points found by the BCP algorithm with respect to the two associated earthquakes occur (20 days and 3 days before, respectively) is not determinant for our investigations, since the dynamics of radon emission is intrinsically complex, as shown also by Jaishi et al. (2014); Kumar et al. (2015); Piersanti et al. (2015). Nevertheless, it could be useful to get further insight into the relationship between radon and seismicity, employing the same BCP algorithm on the cumulative seismic moment release time series, in order to check the possibility of finding significant variations in seismic moment release that are different from the trivial ones (i.e. coincident with a major seismic event). The result is shown in Fig. 9: in this case the rates changes, which are clearly visible a priori, are all found by the algorithm with a probability near to 1 . While the 2nd and the 4th change points clearly identify the two earthquakes, the 1 st and the 3rd change points seem, instead, to identify the beginning of a preparatory phase of the two events. The first occurs on 20 February 2012 (1st red spike in Fig. 9) and the third on 18 August 2012 (3st red spike in Fig. 9). We note that the temporal difference (about 70 days) between each of these two change points and the change points estimated by the BCP algorithm for the MMN time series (the two blue dashed vertical lines in Fig. 9) is comparable. In this respect, radon concentration variations could be sensitive to the internal processes taking place during the preparatory phase of an earthquake.

We point out the fact that a standard change point analysis uses always the whole time series, since to identify a change point at a time $t_{i}$ the algorithm processes also data at $t>t_{i}$. This is a limitation because the algorithm cannot be employed for predictive purposes. To overcome these limitations and most of all to extend the range of our investigations, we implemented an original detection algorithm that potentially could be used in real time analyses. A schematic flow chart of the algorithm is shown in Fig. 10. It basically works on a simple two stage condition: (i) the radon daily average (DA) exceeding by a factor $\left(p_{1}\right)$ the 2 -week moving average (MA) and (ii) the moving average (MA) successively increasing by a factor $\left(p_{3}\right)$ for a given time window $\left(p_{2}\right)$. When both conditions are satisfied, an alarm is issued at day $\left(i+p_{2}\right)$ (red font in box of Fig. 10). If an $M>4.0$ earthquake occurs dur- 


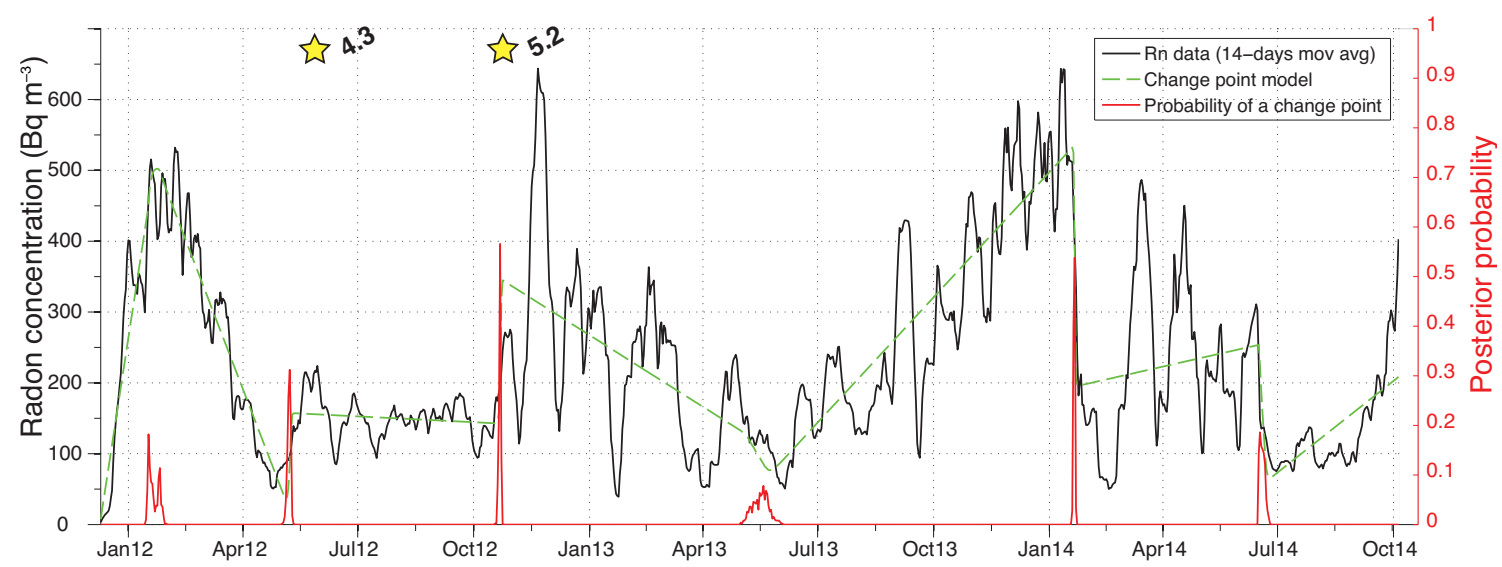

Figure 8. Change point analysis applied to time series of radon concentration at MMN. The black solid line represents the radon concentration at MMN filtered with a 14-day moving average, while the green dashed line represents the model predicted by the Bayesian Change Point (BCP) algorithm. The red line represents the probability of a change point at each time. Yellow stars represent the occurrence of the earthquakes Mw 4.3 on 28 May 2012 and Mw 5.2 on 25 October 2012.

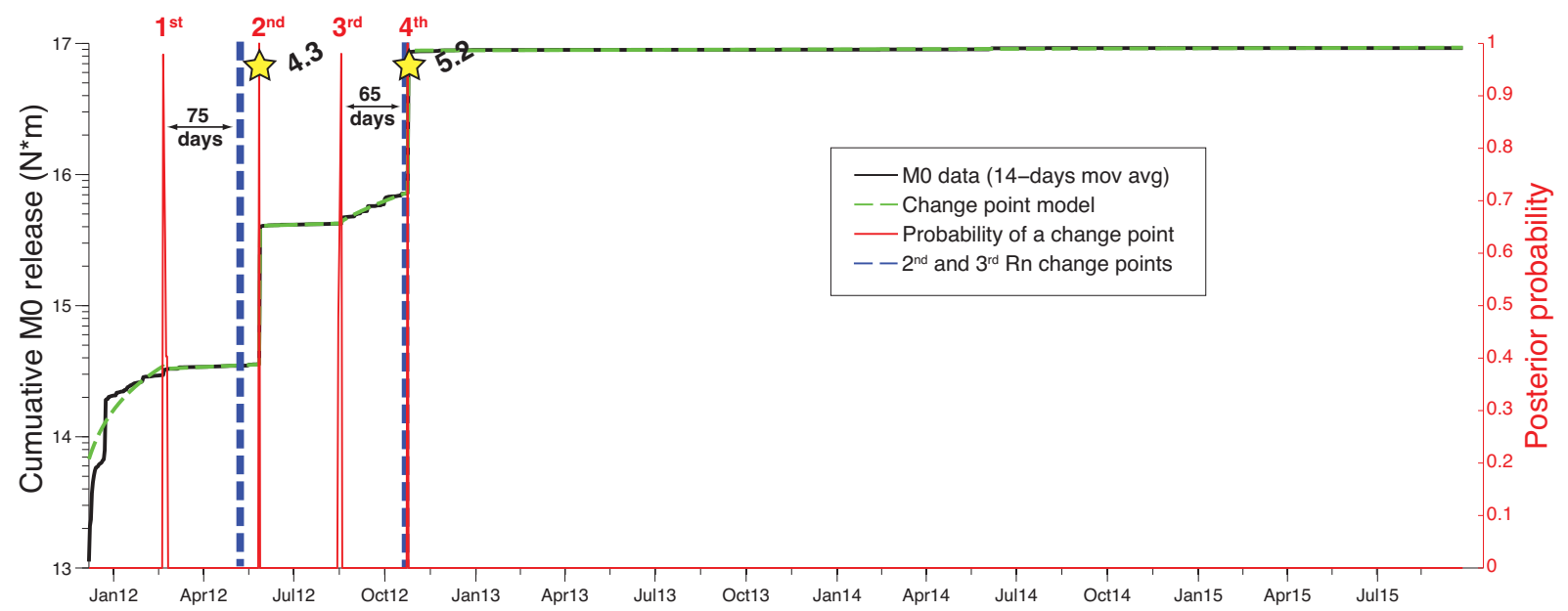

Figure 9. Change point analysis applied to cumulative seismic moment release. The black solid line represents the cumulative seismic moment release filtered with a 14-day moving average, while the green dashed line represents the model predicted by the BCP algorithm. The red curve indicates the probability of a change point at each time. The two blue dashed vertical lines mark the occurrence of the second and of the third change point represented in Fig. 8. Yellow stars represent the occurrence of the earthquakes Mw 4.3 on 28 May 2012 and Mw 5.2 on 25 October 2012.

ing 40 days after the alarm has been issued, all the thresholds to issue subsequent alarms are increased by a factor $\left(p_{4}\right)$ during a time window proportional to the energy released by the event $\left(p_{5}^{M_{\mathrm{EQ}}}\right)$. The algorithm works only with five free parameters, and there is no limitation to the number of alarms that could be issued and to the time when they could be issued.

Figure 11 shows the output of our detection algorithm running on the whole MMN time series. Issued alarms are represented by red triangles, while yellow stars mark the largest seismic events that occurred in the 40 days following the alarm. For each year, the two greatest seismic events have been also displayed (white stars), regardless of the issuing of an alarm. Incidentally, except for 2014, in 2012 and 2013 the two greatest seismic events are just the seismic events that occurred in the 40 days following an alarm. Some main observations can be pointed out here: (i) the algorithm succeeds in forecasting the Mw 5.2 mainshock of October 2012; (ii) it succeeds in forecasting the two main events of the whole sequence (the Mw 5.2 of October 2012 and the Mw 4.3 of May 2012 that started the most active part of the sequence); (iii) it succeeds in forecasting the major events for 2012 and 2013, while it fails for 2014; (iv) it issues only one false alarm in 3 years. We note also that the time advance of the alarms with respect to the earthquake occurrence for the two 


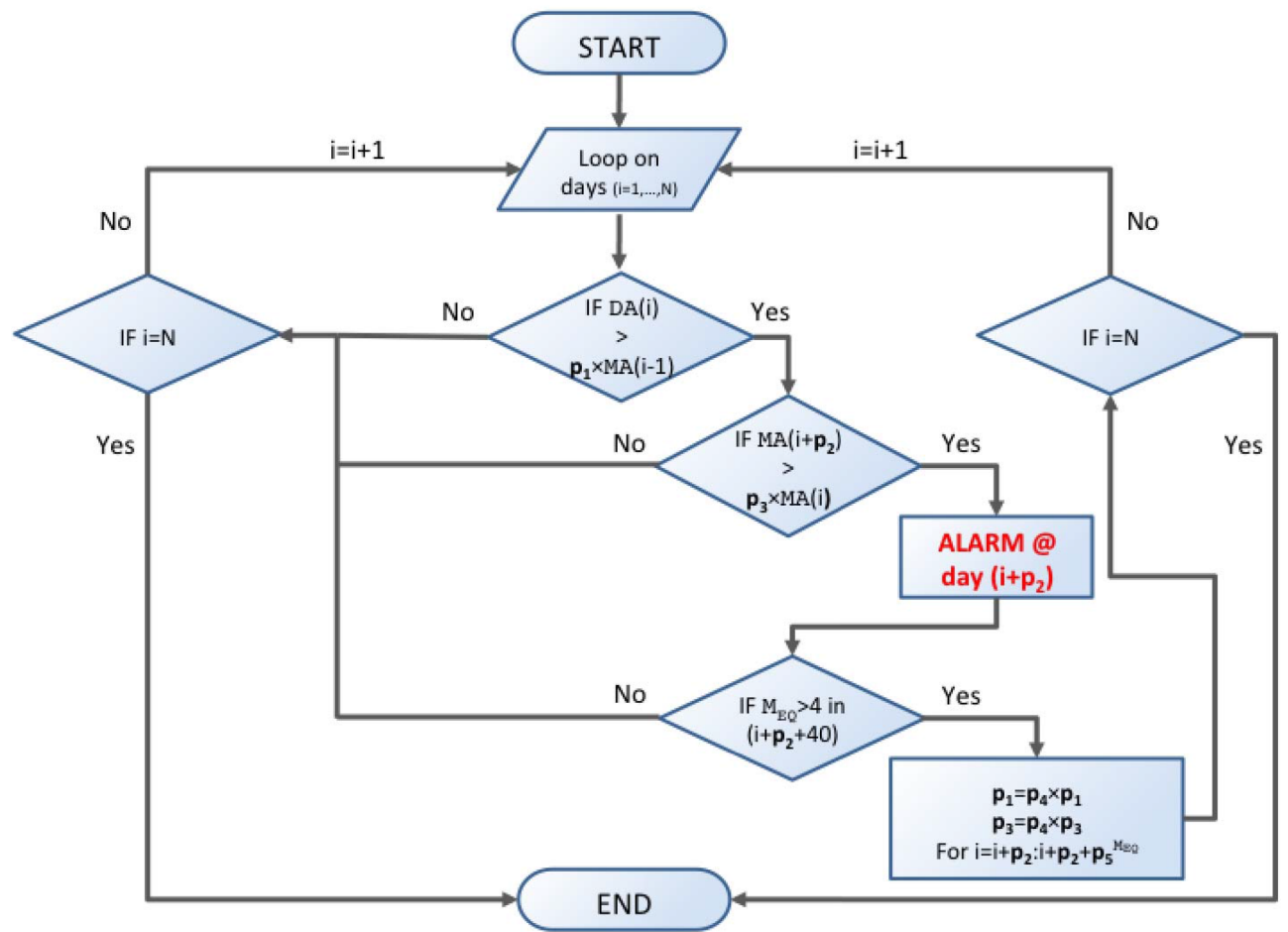

Figure 10. Flow chart representing the detection algorithm. $\left(p_{1}, p_{2}, p_{3}, p_{4}, p_{5}\right)$ are the free five parameters described in the text. DA and $\mathrm{MA}$ are the daily and the 2-week moving average of radon time series, respectively. $M_{\mathrm{EQ}}$ is the magnitude $(>4)$ of the earthquake occurring (if any), during 40 days after the alarm.

main events of the sequence is remarkably similar to that observed by means of change point analysis.

Therefore, both the cross-correlation analysis and the change point analysis, as well as the application of our detection algorithm, indicate that a physical relation between the variation of soil radon emanation and seismic moment release exists. While change point and detection algorithm both succeed in finding some useful radon signal before the variation in seismic moment release, the cross-correlation investigations seem to behold the radon signature after the seismic moment release variation. Relying on the change point analysis and detection algorithm, we have verified if also the cross-correlation analysis is compatible with a radon signal preceding the seismic moment release signal. To investigate this possibility, we have repeated the procedure described in Sect. 3.1. In this case we limit the search domain to positive lag values (i.e. radon signal preceding moment release signal), in order to verify if a suitable solution can be found also in this case. As Fig. 12 highlights, such a solution exists and, comparing Figs. 7 and 12, it is evident that it is only marginally less significant with respect to the best one. Remarkably, as a confirmation of the previous findings, the correction coefficients associated with this solution (see Table 3) are consistent with these found in Sect. 3.1. They indicate for radon observations at MMN station a strong anticorrelation with respect to precipitation $\left(C_{R_{\max }}=9.3\right.$ for tw-
Table 3. The same as Table 2, but limiting the search domain of MINUIT only to positive lag values $(k)$.

\begin{tabular}{rrrrr}
\hline & $C_{T_{\max }}$ & $C_{P_{\max }}$ & $C_{R_{\max }}$ & $w$ \\
\hline $\mathrm{tw}-1$ & 5.6 & 0.9 & 9.3 & 3.0 \\
$\mathrm{tw}-2$ & 2.7 & 1.6 & 10.0 & 3.0 \\
\hline
\end{tabular}

1 and $C_{R_{\max }}=10.0$ for tw-2), a clear anti-correlation with temperature and the lack of a clear correlation with respect to pressure variations.

\section{Conclusive remarks}

We have performed a detailed analysis of the temporal variations of radon emanations from late 2011 to 2014 in a seismically active area during a seismic sequence that culminated at the end of 2012 with a Mw 5.2 event. We exploited several different approaches to carry out our investigations. Namely: (i) phenomenological analysis; (ii) correlation and cross-correlation investigations; (iii) empirical correction of the meteorological parameters effect on radon time series and its impact on cross-correlation; (iv) change point analysis; (v) detection algorithm. 


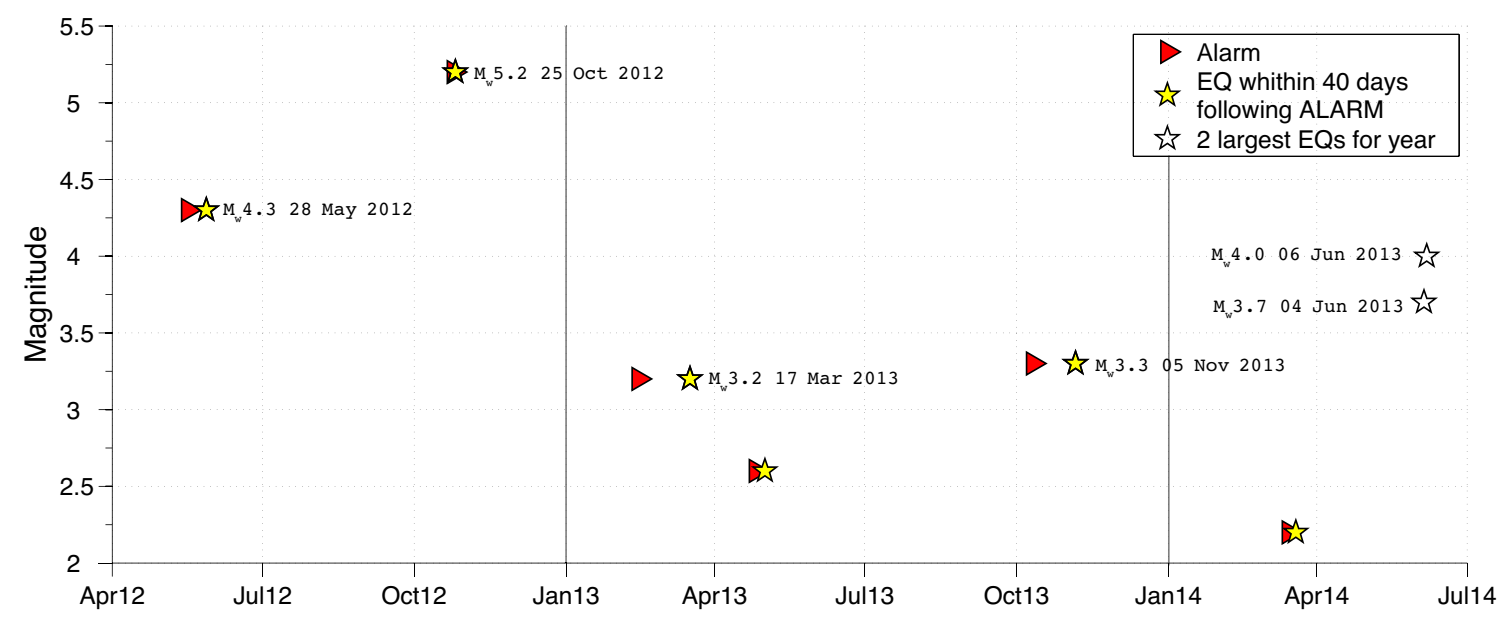

Figure 11. Output of the detection algorithm applied to time series of radon concentration at MMN. The red triangles represent all the issued alarms, yellow stars represent the greatest seismic events occurred in the 40 days following each alarm. For each year the two greatest seismic events have been also displayed (white stars), with corresponding occurrence date and magnitude.

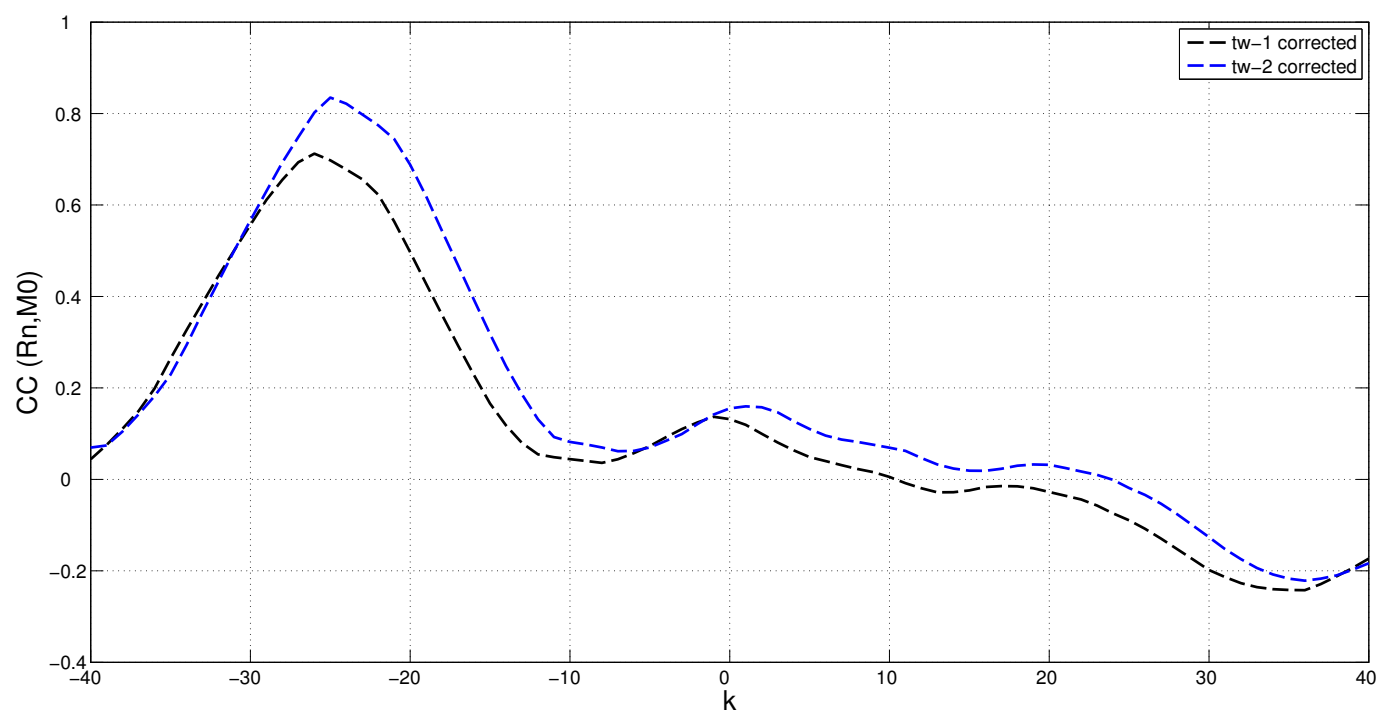

Figure 12. The same as Fig. 7, but limiting the search domain of MINUIT only to positive lag values $(k)$ (the corresponding correction coefficients are reported in Table 3).

We can split the main results of our work in two classes: (a) those concerning the impact of meteorological parameters variation on the observed radon time series and (b) those concerning the existence of a physical connection between the observed radon time series and the seismic moment release temporal variations. Converging indications coming from both classes represent an important outcome of our work. Regarding class (a), we have indications that, in the investigated setting, soil radon emanation is strongly anti-correlated with precipitation and weakly anti-correlated with temperature, while we do not get significant and univocal evidence of correlation (positive or negative) with pressure variations. In this context, approaches (i), (ii) and (iii) give remarkably consistent indications and we see as particularly significant the agreement between the strength of the correlation evidenced by (i) and (ii) and the magnitude of the corresponding correction factor found with (iii). These results, when compared with previous findings, confirm that the environmental impact on radon observations is strongly site dependent. The correlation between radon variations and temperature is, in this sense, a clear example: many works found it positive, as several others (including ours), negative. This observation suggests that a specific characterization is needed for each station, when implementing an observational network (see, for example, the dependence on the varying soil characteristics as porosity, permeability, and pre-rain moisture state). 
Regarding class (b), all of our analyses univocally indicate the existence of a non-accidental correlation between the temporal evolution of soil radon emanation and seismic moment release. The primary output of approach (ii) suggests that the radon signal follows the seismic moment variation, while approaches (i), (iv) and (v) indicate that it is possible to retrieve the radon signal also before the seismic moment variation. Remarkably, we have found that even if approach (ii) gives as primary result a shifted forward temporal correlation also the solution with the radon signal preceding the seismic moment variation is acceptable at a barely lower significance level.

\section{The Supplement related to this article is available online at doi:10.5194/se-7-1303-2016-supplement.}

Acknowledgements. We thank P. Einarsson and R. C. Tiwari for their constructive comments and careful reviews. We are grateful to F. Pio Lucente for discussion about the Pollino 2010 seismic sequence.

Edited by: I. Koulakov

Reviewed by: P. Einarsson and R. C. Tiwari

\section{References}

Abbady, A., Abbady, A. G. E., and Michel, R.: Indoor radon measurement with The Lucas cell technique, Appl. Radiat. Isotopes, 61, 1469-1475, 2004.

Bourcier, W. L., Wolery, T. J., Wolfe, T., Haussmann, C., Buscheck, T. A., and Aines, R. D.: A preliminary cost and engineering estimate for desalinating produced formation water associated with carbon dioxide capture and storage, Int. J. Green. Gas Con., 5, 1319-1328, doi:10.1016/j.ijggc.2011.06.001, 2011.

Box, G. E. P., and Jenkins, G. M.: Time Series Analysis, Forecasting and Control, Holden-Day Inc., San Francisco, 1976.

Cannata, A., Giudice, G., Gurrieri, S., Montalto, P., Alparone, S., Grazia, G., Favara, R., Gresta, S., and Liuzzo, M.: Relationship between soil $\mathrm{CO}_{2}$ flux and volcanic tremor at Mt. Etna: Implications for magma dynamics, Environ. Earth Sci., 61, 477-489, 2009

Celia, M. A., Bachu, S., Nordbotten, J. M., and Bandilla, K. W.: Status of $\mathrm{CO}_{2}$ storage in deep saline aquifers with emphasis on modeling approaches and practical simulations, Water Resour. Res., 51, 6846-6892, 2015.

Chatfield, C.: The Analysis of Time series, An Introduction, sixth edition Chapman and Hall/CRC, New York, 333 pp., 2004.

Chlieh, M., De Chabalier, J. B., Ruegg, J. C., Armijo, R., Dmowska, R., Campos, J., and Feigl, K. L.: Crustal deformation and fault slip during the seismic cycle in the North Chile subduction zone, from GPS and InSAR observations, Geophys. J. Int., 158, 695711,2004

Cicerone, R. D., Ebel J. E., and Britton, J.: A systematic compilation of earthquake precursors, Tectonophysics, 476, 371-396, 2004.
Cinti, F. R., Cucci, L., Pantosti, D., D’Addezio, G., and Meghraoui, M.: A major seismogenic fault in a "silent area": The Castrovillari fault (southern Apennines, Italy), Geophys. J. Int., 130, 595-605, 1997.

Cinti, F. R., Moro, M., Pantosti, D., Cucci, L., and D'Addezio, G.: New constraints on the seismic history of the Castrovillari fault in the Pollino gap (Calabria, southern Italy), J. Seismol., 6, 199217, 2002.

Cinti, F. R., Alfonsi, L., D'Alessio, A., Marino, S., and Brunori, C. A.: Faulting and ancient earthquakes at Sybaris archaeological site, Ionian Calabria, southern Italy, Seismol. Res. Lett, 86, 245 254, 2015.

Dobrovolsky, I. P., Zubkov, S. I., and Miachkin, V. I.: Estimation of the size of earthquake preparation zones, Pure Appl. Geophys. 117, 1025-1044, 1979

Einarsson, P., Theodorsson, P., Hjartardottir,A. R., and Guojonsson, G. I.: Radon anomalies associated with the earthquakes sequence in June 2000 in the South Iceland Seismic Zone, Pure Appl. Geophys., 165, 63-74, 2008.

Federico, S., Avolio, E., Pasqualoni, L., and Bellecci, C.: Atmospheric patterns for heavy rain events in Calabria, Nat. Hazards Earth Syst. Sci., 8, 1173-1186, doi:10.5194/nhess-8-1173-2008, 2008.

Fletcher, R.: A new approach to variable metric algorithms, Comput. J., 13, 317-322, 1970 .

Fuchs, F., Lupi, M., and Miller, S. A.: Remotely triggered nonvolcanic tremor in Sumbawa, Indonesia, Geophys. Res. Lett., 41, 4185-4193, 2014.

Guilhem, A., Peng, Z., and Nadeau, R. M.: High-frequency identification of non-volcanic tremor triggered by regional earthquakes, Geophys. Res. Lett., 37, L16309, doi:10.1029/2010GL044660, 2010.

Hollander, M., Wolfe, D. A., and Chicken, E.: Nonparametric Statistical Methods, 3rd Edn., Wiley, 2014.

Hauksson, E. and Goddard, J.: Radon Earthquake Precursor Studies in Iceland, J. Geophys. Res., 86, 7037-7054, 1981.

Inan, S., Kop, A., Cetin, H., Kulak, F., Pabuccu, Z., Seyis, C., Ergintav, S., Tan, O., Saatcilar, R., and Bodur, M. N.: Seasonal variations in soil radon emanation: long-term continuous monitoring in light of seismicity, Nat. Hazards, 62, 575-591, 2012.

Italian Seismological Instrumental and Parametric Database [ISIDe] Working Group: available from: http://iside.rm.ingv.it (last access: May 2016), 2010.

Iskandar, D., Yamazawa, H., and Iida, T.: Quantification of the dependency of radon emanation power on soil temperature, Appl. Radiat. Isot., 60, 971-973, 2004.

Jaishi, H., Singh, S., Tiwari, R. P., and Tiwari, R. C.: Analysis of soil radon data in earthquake precursory studies, Ann. Geophys., 57, S0544, doi:10.4401/ag-6513, 2014.

James, F.: MINUIT: Function Minimization and Error Analysis, 100 CERN Program Library Long Writeup D506; available at: http: //consult.cern.ch/writeup/minuit/, last access: April 1998.

Jebur, M. N., Pradhan, B., and Tehrany, M. S.: Detection of vertical slope movement in highly vegetated tropical area of Gunung pass landslide, Malaysia, using L-band InSAR technique, Geosci. J., 18, 61-68, 2014.

Kendall, M. G.: Rank Correlation Methods, 2nd Edn., New York, Hafner, 1970. 
Kumar, A., Walia, V., Arora, B., Yang, T., Lin, S.-J., Fu, C.-C., Chen, C.-H., and Wen, K.-L.: Identifications and removal of diurnal and semidiurnal variations in radon time series data of Hsinhua monitoring station in SW Taiwan using singular spectrum analysis, Nat. Hazards, 79, 317-330, 2015.

Lewicki, J. L., Hilley, G. E., Shelly, D. R., King, J. C., McGeehin, J. P., Mangan, M., and Evans, W. C.: Crustal migration of $\mathrm{CO} 2$-rich magmatic fluids recorded by tree-ring radiocarbon and seismicity at Mammoth Mountain, CA, USA, Earth Planet. Sc. Lett., 390, 52-58, 2014.

Liu, G. X., Ding, X. L., Li, Z. L., Li, Z. W., Chen, Y. Q., and Yu, S. B.: Pre- and co-seismic ground deformations of the 1999 Chi-Chi, Taiwan earthquake, measured with SAR interferometry, Comput. Geosci., 30, 333-343, 2004.

Lucas, H. F.: Improved Low-Level Alpha-Scintillation Counter for Radon, Rev. Sci. Instrum., 28, 680-683, 1957.

Lucente, F., De Gori, P., Margheriti, L., Piccinini, D., Di Bona, M., Chiarabba, C., and Agostinetti, N. P.: Temporal variation of seismic velocity and anisotropy before the 2009 MW 6.3 L'Aquila earthquake, Italy, Italy, Geology, 38, 1015-1018, 2010.

Michetti, A. M., Ferreli, L., Serva, L., and Vittori, E.: Geological evidence for strong historical earthquakes in an "aseismic" region: The Pollino case (southern Italy), J. Geodyn., 24, 61-86, 1997.

Michetti, A. M., Ferreli, L., Esposito, E., Porfido, S., Blumetti, A. M., Vittori, E., Serva, L., and Roberts, G. P.: Ground effects during the 9 September 1998, Mw 5.6 Lauria earthquake and the seismic potential of the "aseismic" Pollino region in southern Italy, Seismol. Res. Lett., 71, 31-46, 2000.

Miller, S. A., Collettini, C., Chiaraluce, L., Cocco, M., Barchi, M., and Kaus, B. J. P.: Aftershocks driven by a high-pressure $\mathrm{CO}_{2}$ source at depth, Nature, 427, 724-727, 2004.

Mollo, S., Tuccimei, P., Heap, M. J., Vinciguerra, S., Soligo, M., Castelluccio, M., Scarlato, P., and Dingwell, D. B.: Increase in radon emission due to rock failure: An experimental study, Geophys. Res. Lett., 38, L14304, doi:10.1029/2011GL047962, 2011.

Oh, Y. and Kim, G.: A radon-thoron isotope pair as a reliable earthquake precursor, Sci. Rep., 5, 13084, doi:10.1038/srep13084, 2015.

Piersanti, A., Cannelli, V., and Galli, G.: Long term continuous radon monitoring in a seismically active area, Ann. Geophys., 58, S0437, doi:10.4401/ag-6735, 2015.

Pitari G., Coppari, E., De Luca, N., and Di Carlo, P.: Observations and box model analysis of radon-222 in the atmospheric surface layer at L'Aquila, Italy: March 2009 case study, Environ. Earth Sci., 71, 2353-2359, 2014.

Reeves, J., Chen, J., Wang, X. L., Lund, R. B., and Lu, Q.: A review and comparison of changepoint detection techniques for climate data, J. Appl. Meteor. Climatol., 46, 900-915, 2007.

Ruggieri, E.: A Bayesian Approach to Detecting change Points in Climatic Records, Int. J. Climatol., 33, 520-528, 2013.

Semkow, T. M., Parekh, P. P., Schwenker, C. D., Dansereau R., and Webber, J. S. Efficiency of the Lucas scintillation cell, Nucl. Instrum. Methods A, 353, 515-518, 1994.

Shelly, D. R., Taira, T., Prejean, S. G., Hill, D. P., and Dreger, D. S.: Fluid-faulting interactions: Fracture-mesh and fault-valve behavior in the February 2014 Mammoth Mountain, California, earthquake swarm, Geophys. Res. Lett., 42, 5803-5812, 2015.
Singh, M., Ramola, R. C., Singh, N. P., Singh, S., and Virk, H. S.: Influence of meteorological parameters on soil gas radon, J. Assoc. Explor. Geophys., 9, 85-90, 1988.

Snedecor, G. W. and W. G. Cochran (1989), Statistical methods, eighth edition, 803 pp., Iowa State University Press, Ames, Iowa.

Spagnuolo, E., Plumper, O., Violay, M., Cavallo, A., and Di Toro, G.: Fast-moving dislocations trigger flash weakening in carbonate-bearing faults during earthquakes, Scientific Reports, 5, 16112, doi:10.1038/srep16112, 2015.

Stefansson, R.: Advances in Earthquake Prediction, SpringerVerlag, Berlin, Heidelberg, 300 pp., doi:10.1007/978-3-54047571-2, 2011.

Terranova, O. G. and Iaquinta, P.: Temporal properties of rainfall events in Calabria (southern Italy), Nat. Hazards Earth Syst. Sci., 11, 751-757, doi:10.5194/nhess-11-751-2011, 2011.

Tertulliani, A., and Cucci, L.: New insights on the strongest historical earthquake in the Pollino region (southern Italy), Seismol. Res. Lett., 85, 743-751, 2014.

Totaro, C., Presti, D., Billi, A., Gervasi, A., Orecchio, B., Guerra, I., and Neri, G.: The ongoing seismic sequence at the Pollino Mountains, Seismol. Res. Lett., 84, 955-962, 2014.

Totaro, C., Seeber, L., Waldhauser, F., Steckler, M., Gervasi, A., Guerra, I., Orecchio, B., and Presti, D.: An Intense Earthquake Swarm in the Southernmost Apennines: Fault Architecture from High-Resolution Hypocenters and Focal Mechanisms, Bull. Seismol. Soc. Am., 105, 3121, doi:10.1785/0120150074, 2015.

Tserolas, V., Mertikas, S. P., and Frantzis, X.: The Western Crete geodetic infrastructure: long-range power-law correlations in GPS time series using detrended fluctuation analysis, Adv. Space Res., 51, 1448-1467, 2012.

Tuccimei, P., Mollo, S., Vinciguerra, S., Castelluccio, M., and Soligo, M.: Radon and thoron emission from lithophysae-rich tuff under increasing deformation: An experimental study, Geophys. Res. Lett., 37, L05305, doi:10.1029/2009GL042134, 2010.

Tuccimei, P., Mollo, S., Soligo, M., Scarlato, P., and Castelluccio, M.: Real-time setup to measure radon emission during rock deformation: implications for geochemical surveillance, Geosci. Instrum. Method. Data Syst., 4, 111-119, 2015.

Vennari, C., Gariano, S. L., Antronico, L., Brunetti, M. T., Iovine, G., Peruccacci, S., Terranova, O., and Guzzetti, F.: Rainfall thresholds for shallow landslide occurrence in Calabria, southern Italy, Nat. Hazards Earth Syst. Sci., 14, 317-330, doi:10.5194/nhess-14-317-2014, 2014.

Zafrir, H., Barbosa, S. M., and Malik, U.: Differentiation between the effect of temperature and pressure on radon within subsurface geological media, Radia. Meas., 49, 39-59, 2013.

Zmazek, B., Todorovski, L., Dmeroski, S., Vaupotic, J., and Kobal, I.: Application of decision trees to the analysis of soil radon data for earthquake prediction, Appl. Radiat. Isot., 58, 697-706, 2003. 